Hydraulic Engineering Repository

Ein Service der Bundesanstalt für Wasserbau

Chevalier, Christophe; Haghighi, I.; Pham, Tuan Long; Reiffsteck, Philippe Two Complementary Tests for Characterizing the Soil Erosion

Verfügbar unter / Available at:

https://hdl.handle.net/20.500.11970/100239

Vorgeschlagene Zitierweise / Suggested citation:

Chevalier, Christophe; Haghighi, I.; Pham, Tuan Long; Reiffsteck, Philippe (2010): Two Complementary Tests for Characterizing the Soil Erosion. In: Burns, Susan E.; Bhatia, Shobha K.; Avila, Catherine M. C.; Hunt, Beatrice E. (Hg.): Proceedings 5th International Conference on Scour and Erosion (ICSE-5), November 7-10, 2010, San Francisco, USA. Reston, Va.: American Society of Civil Engineers. S. 152-161. 


\title{
Two Complementary Tests for Characterizing the Soil Erosion
}

\author{
C. Chevalier ${ }^{1}$, I. Haghighi ${ }^{2}$, T.L. Pham ${ }^{2}$, Ph. Reiffsteck ${ }^{3}$
}

Université Paris-Est, LCPC, GER, 58 boulevard Lefebvre, 75015 Paris, France;

${ }^{1} \mathrm{PH}+331404352$ 16; email: christophe.chevalier@lcpc.fr

${ }^{2} \mathrm{PH}+331404352$ 76; email: iman.haghighi@1cpc.fr

${ }^{3} \mathrm{PH}+331404352$ 73; email: philippe.reiffsteck@1cpc.fr

\begin{abstract}
For estimating sensitivity of soils to erosion, the Hole Erosion Test (HET) has proved to be an efficient and convenient laboratory apparatus. Measuring sensitivity to erosion in situ with dedicated tests like the Mobile Jets Erosion Test (MoJET) is also of great interest since it allows testing the soil in its real state. However, results are generally not easily linked between laboratory and in situ tests and this is a great shortcoming of theses methods. The presented study is based on comparative tests with Hole Erosion Test and Mobile Jets Erosion Test apparatus, and tries to address this need. In this purpose, different remolded textures of soil were tested in order to cover a wide variety of situations. Thus, erosion parameters obtained from HET (erosion coefficient and critical shear stress) can be qualitatively linked to MoJET data (initial erosion rate and final eroded mass).
\end{abstract}

Keywords: Soil erosion, Piping, Surface erosion, Laboratory tests, Parametric study

\section{INTRODUCTION}

Recent catastrophic floods occurred among others in France (French county Aude in November 1999 or Gard in September 2002) clearly show the great vulnerability of embankments and dikes to internal erosion and overtopping. The surface and internal erosion do not always lead directly to failure of the structures, but may do so by reducing its overall stability under the working load and water flow. Combinations of these phenomena, if they last long enough may lead to breaching the embankment. It should also be recognized that unlike modern dams, the internal structure of these road and rail embankments and some old dikes dating from the French renaissance were not designed with filters and surface erosion protection (Guiton 1998).

This paper presents the study of reproducible erosive tests using two different apparatus: the recently proposed "Hole Erosion Test" (HET) (ASTM 2005a, Perry 1979, Pham 2008, Pham et al. 2010, Wan and Fell 2002, 2004) and the LCPC "Mobile Jets Erosion Test" (MoJET) (Henensal and Duchatel 1990, Pham 2008) that can be used either in laboratory or in the field. Tests have been carried out with soils prepared with various ground textures and the results have been compared. The results can so be used to establish directives supplementing the actual design guides for road or landscape management (CFG 2004, LCPC and SETRA 1992).

This paper is organized as follow. In a first part (section 2), basic features of the Hole Erosion Test (section 2.1) and the Mobile Jets Erosion Test (section 2.2) are given such as the description of the ground texture used for conducting the both tests 
(section 2.3). In a second part (section 3), results are presented for the both tests (HET section 3.1 and MoJET section 3.2) and comparisons are finally made (section 4). Conclusion and perspectives are drawn in a last part (section 5).

\section{TESTING METHODS AND MATERIALS}

Laboratory erosion tests are a convenient way to understand how various factors affect the complicated process of soil erosion. It is easy in the laboratory to collect runoff water in a measuring tank and to measure the quantity of eroded soil. Many apparatus able to produce an artificial erosion of a soil surface have been thus developed in the past decades (Arulanandan et al. 1980, Bendahmane et al. 2006, Sanchez et al. 1983, Wan and Fell 2002, 2004).

However, tests that can be done in the field are of great interest because they allow testing of the soil in its real initial state with the ability to repeat the test on the structure close to a breach. This is the case of the jet erosion test developed by Hanson (2004) and the MoJET developed at LCPC by Hénensal and Duchatel (1990).

We used in this study a modified version of the HET and the LCPC MoJET to compare results on soils prepared with various ground textures.

\section{Hole Erosion Test (HET)}

In order to quantitatively characterize the piping erosion, the Hole Erosion Test recently developed by Wan and Fell $(2002,2004)$ was a great understanding step forward.

We recently design and develop our own HET device (Pham 2008, Pham et al. 2010, Reiffsteck et al. 2006). Similar to the one developed by Wan and Fell, it presents a number of improvements designed to make it easier to use and more comprehensive for measuring parameters of erosion.

\section{Apparatus}

The HET device has three parts: an upstream water tank, an eroding unit where the sample is located (Fig. 1) and a downstream water exit.

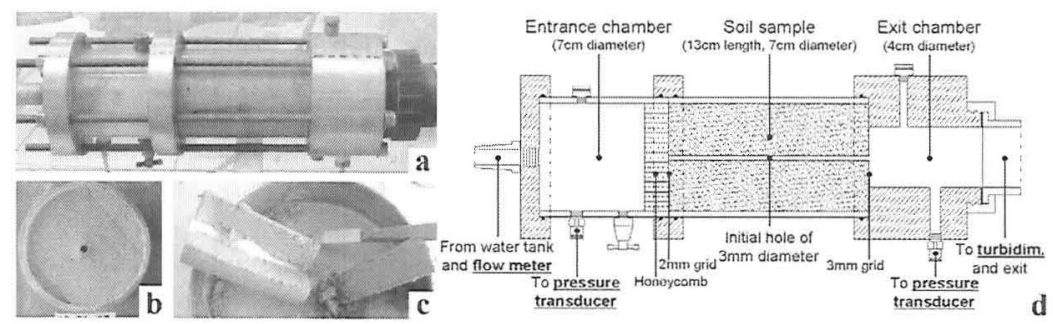

Figure 1. Hole erosion test set-up. (a) Image of eroding unit. (b) Sample before test with $3 \mathrm{~mm}$ diameter hole. (c) Cut sample after test with molded wax. (d) Drawing of eroding unit. Sensors are indicated in bold and underlined characters. 
The upstream tank is a PVC cylinder of 80 liters volume. It can be pressurized by air and recharged with water during the test. A turbine flow meter is placed in the vicinity of the eroding unit.

The column of water downstream is constant at $20 \mathrm{~cm}$.

The eroding unit is depicted on figures $1(\mathrm{a}-\mathrm{d})$. It includes three parts. The first part is the entrance chamber of water. In addition to a first miniature pressure transducer, this part includes a honeycomb in order to reduce swirl in entry hole as well as a grid of $2 \mathrm{~mm}$. The second part consists of the soil sample itself with a hole of $3 \mathrm{~mm}$ in diameter. The Plexiglas transparent mold allows checking that no unexpected erosion occurs between the sample and the mold. The third part is the exit room. This section includes a second miniature pressure transducer. A turbidimeter is placed right after this part in order to measure the turbidity of the fluid out of the specimen.

\section{Procedure}

Soil samples are prepared into a cylindrical Plexiglas mold. The dimensions are $7 \mathrm{~cm}$ in diameter and $13 \mathrm{~cm}$ in length (volume: $500 \mathrm{~cm} 3$ ). The soil is prepared in advance at given water content. Water content and final density are generally defined using a standard Proctor test (ASTM 2005b) for comparison with practical conditions in embankments. The initial hole of $3 \mathrm{~mm}$ diameter in the middle of the sample is finally achieved with a vertical drill (Fig. 1b).

After bringing water in all the system and especially in the sample, the air pressure in the upstream water reservoir is raised gradually until the desired pressure drop at the sample is reached. As erosion occurs, the sample hole grows during the test and the water flow increases. This increasing flow induces that head loss in the upstream hydraulic system increases then the pressure in the water reservoir is also increased and the pressure drop $\Delta P$ at the sample boundaries is maintained constant. When the total head loss of the hydraulic system is too large, increasing pressure in the reservoir is no longer sufficient to maintain a constant pressure drop in the sample. This happens when the diameter of the hole is nearly the same as the pipes diameter supplying the circuit. The pressure in the tank is slowly reduced and then reduced to zero.

The sample of eroded soil is then taken out of the device and molten wax is poured into the eroded hole. The sample is cut out and the "candle" is prudently extracted (Fig. 1c). This "candle" represents the shape of the hole of the sample after erosion. The volume allows calculating the final average radius of the eroded hole.

During the entire test, from the increase of head charge to the decrease, the data collected by flow meter (flow rate $Q$ ), pressure transducers (pressure drop $\Delta P$ ) and turbidimeter (turbidity $T$ ) are stored on a computer using a datalogger. The frequency of acquisition is generally used $1 \mathrm{~Hz}$. These measurements and data on initial and final radii allow calculating erosion curves [interpretation method detailed in (Pham 2008, Pham et al. 2010)] i.e. the relationship between the two following physical quantities:

- the shear stress $\tau$, that the flowing liquid applies on the interface (SI unit: $\mathrm{Pa})$, 
- the erosion rate $\dot{\varepsilon}$, that represents the mass of soil eroded per unit area and time (SI unit: $\mathrm{kg} \cdot \mathrm{m}^{-2} \cdot \mathrm{s}^{-1}$ ).

\section{Mobile Jets Erosion Test (MoJET)}

The development of a specific testing apparatus of rotary type called "Mobile Jets Erosion Test" (Fig. 2) was the consequence of research undertaken by LCPC in the 1990's. This work was aimed partly to correlate the soil sensitivity to erosion with laboratory parameters such as plasticity index, methylene blue value, activity, texture and friction angle (Henensal 1993, Henensal and Duchatel, 1990). This apparatus can be implemented on site or used in laboratory and is thus well adapted for comparison with laboratory tests such as previously described Hole Erosion Test.

\section{Apparatus}

The mobile water jets test apparatus consists of an active mechanical part, called the "eroding unit", a water tank under controlled air pressure, and various additional units. The eroding unit projects water jets with $0.5 \mathrm{~mm}$ diameter nozzles (Fig. 2a) perpendicular to the soil surface which one wants to measure the sensitivity to erosion. Six water jets of similar and well defined characteristics are used. The geometry of this apparatus is quite similar to the submerged jet device developed by Hanson $(1993,2004)$. However in the LCPC apparatus, the soil is not fully submerged and the arm of the eroding unit, providing a mount for the six jet nozzles, rotates during the test.

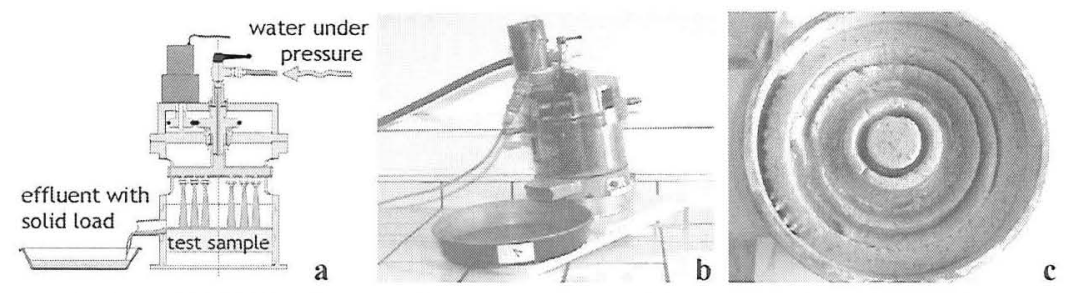

Figure 2. Mobile jets erosion test set-up. (a) Drawing of eroding unit. (b) Image of eroding unit. (c) Sample after test.

\section{Procedure}

The first stage of the test procedure is to bring the sample to a given density by static compaction. The sample in its mould is then inserted in the apparatus, which is connected with the pressurized water source. The mould is placed on a $10 \%$ slope ( 6 degree) used for the test (Fig. 2b). The outfall ring is inserted on the mould while directing the outfall towards the downstream of the slope into the top of the measurement container (Fig. 2b). The ground is then subjected to the action of the water jets with the following test parameters:

- air pressure in the water tank: $20 \pm 2 \mathrm{kPa}$, imposing flow rate,

- duration of the experiment: 12 minutes with sampling of the whole effluent at $1,2,4,8$ and 12 minutes. 
After the test, the soil sample shows gullies located where the water jets impact its surface (Fig. 2c).

The quantity of effluent collected for the different times is passed to the drying oven and measured to determine the mass of dry material eroded (Pham 2008). This solid load (i.e. eroded mass as a function of time) can be used to perform qualitative evaluations of erosion, to establish correlations between the amount of soil erosion and the geotechnical properties or to compare the various soil behaviors.

\section{Tested Materials}

Different reconstituted textures of soil were tested in order to cover a wide variety of situations.

The textures are made from a mixture of sand, silt and kaolinite clay, to which is added a water content corresponding to $95 \%$ of Normal Proctor Optimum (ASTM 2005b). Kaolinite was used as it is a common type of clay in France. These soil textures are positioned on the ternary diagram of USCS classifications (Fig. 3a). The physical characteristics are reported in table 1 and the particle size distribution is shown on Fig. 3b. These textures cover a wide range from the clayey to the sandy soils.

It should be noted that samples are unsaturated and compacted as prepared at $95 \%$ of Normal Proctor Optimum (ASTM 2005b). This choice was made in this study as this is the typical state of materials for road or railway embankments. Anyway, the purpose of the present work is to focus on the comparison of two tests, HET and MoJET, using different soil textures and not to report a detailed study on the relative sensitivity of soils to erosion phenomena.
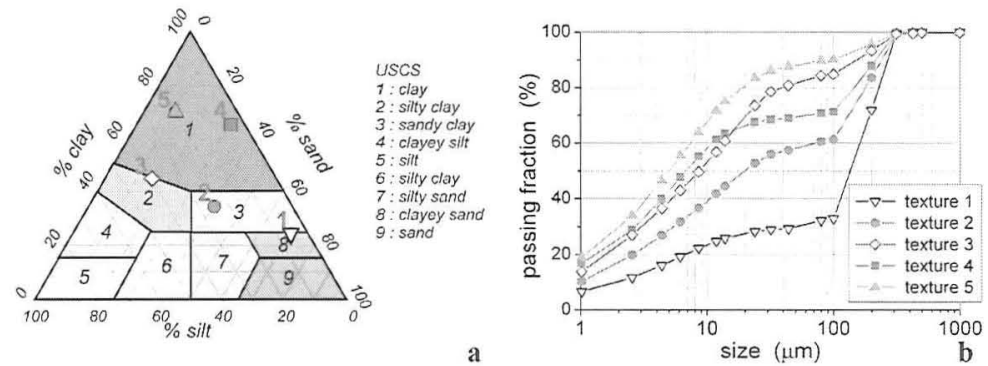

Figure 3. Tested textures. (a) ternary diagram and (b) particle size distribution.

Table 1. Tested textures: components and physical characteristics.

\begin{tabular}{c|c|c|c|c|c|c|c|c}
\hline \multirow{2}{*}{ texture } & \multicolumn{2}{|c|}{ dry mass fraction (\%) } & water & dry & \multicolumn{3}{c}{ liq/plastic limits } \\
& clay & silt & sand & $(\%)$ & density & $\mathrm{w}_{\mathrm{L}}(\%)$ & $\mathrm{w}_{\mathrm{P}}(\%)$ & $\mathrm{IP}(\%)$ \\
\hline 1 & 25 & 5 & 70 & 11 & 2.1 & 13.5 & - & - \\
\hline 2 & 35 & 25 & 40 & 11 & 1.95 & 19.6 & 13.9 & 5.7 \\
\hline 3 & 45 & 40 & 15 & 14 & 1.9 & 26.9 & 20.4 & 6.5 \\
\hline 4 & 65 & 5 & 30 & 19 & 1.8 & 26.1 & 21.7 & 4.4 \\
\hline 5 & 70 & 20 & 10 & 26 & 1.85 & 35.2 & 30.0 & 5.2 \\
\hline
\end{tabular}




\section{RESULTS}

\section{Hole Erosion Test (HET)}

The results of Hole Erosion Test on the specified textures are represented on figure 4. It represents the erosion rate $\dot{\varepsilon}$ as a function of the shear stress $\tau$ at the interface. It should be noted that, for each soil textures, experimental data points were obtained from repeatable tests and also for different pressure drops (Pham 2008, Pham et al. 2010).

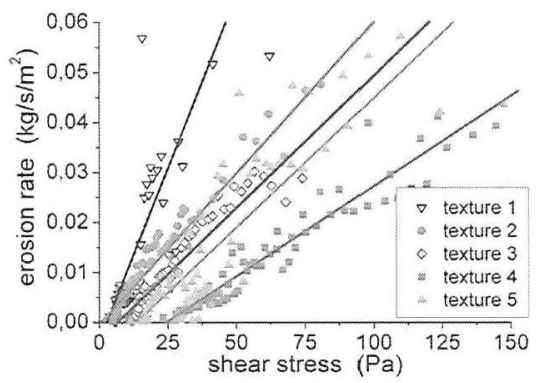

Figure 4. Experimental data and fit of Hole Erosion Test for the different textures.

As underlined in previous experimental and theoretical work (Bonelli et al. 2006, Wan and Fell 2002, 2004), data can be fitted with empirical linear laws with threshold:

$$
\dot{\varepsilon}=k_{e r}\left(\tau-\tau_{c}\right),
$$

where $\tau_{c}$ is the critical shear stress and $k_{e r}$ the erosion coefficient. These coefficients thereafter characterize the erosion process occurring in the HET.

Experimental data for the different soil samples can be easily separated and HET allows well separating the behavior of the different textures. In particular, the texture 1 on one side and the texture 4 on the other are very well distinct from the textures 2,3 or 5 : the texture 1 presents clearly the higher sensitivity to erosion and the texture 4 is the most resistant. It could be noted that whereas the textures 4 and 5 have comparable characteristics (especially for the clay content), they present a really different sensitivity to erosion.

\section{Mobile Jets Erosion Test (MoJET)}

The results of Mobile Jets Erosion Test on the specified textures are represented on the figures $5(\mathrm{a}, \mathrm{b})$. Figure $5(\mathrm{a})$ shows the cumulated eroded mass as a function of time whereas figure 5(b) represent the erosion rate, i.e. the eroded mass by unit of time. Experimental data show a rather good repeatability even if the test is relatively simple. 

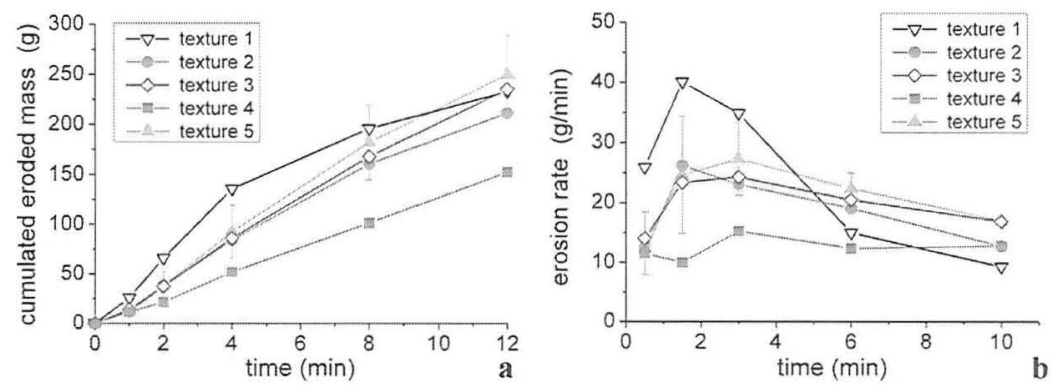

Figure 5. Experimental data of Mobile Jets Erosion Test for the different textures: (a) cumulated eroded mass and (b) erosion rate as functions of time.

Curves on figure 5(b) present two phases. In the first time of the test, there is an increase of the erosion rate corresponding at the initiation and the set-up of the erosion processes. Thereafter, erosion rate decreases as the gullies (see Fig. 2c) are deeper and so the stress applied on their surface decreases.

Experimental data for some soil samples show distinct characteristics even if the MoJET does not allow separating the behavior of all the different textures. In particular, the texture 1 on one side and the texture 4 on the other are very well distinct from the textures 2,3 or 5 like as already shown with HET: the texture 1 presents clearly the higher sensitivity to erosion and the texture 4 is the most resistant.

\section{COMPARISON OF HET AND MoJET}

The characteristics of erosion curves obtained with HET are well defined. In particular, the sensitivity to erosion can be evaluated thanks to the critical shear stress and the erosion coefficient. Concerning the MoJET, even if the test is convenient and the erosion curves are relatively easy to explain, the deduction from theses curves to simple erosion parameters is far from trivial. We thus seek to link both tests by a simple approach of the mechanisms occurring in the MoJET.

\section{Erosion Coefficient (HET) and Initial Erosion Rate (MoJET)}

One of the two parameters characterizing HET is the erosion coefficient $k_{e r}$. It is the only parameter that characterizes the erosion for shear stresses far from the threshold. Figure 6(a) represents the erosion coefficient obtained from HET for the different textures.

For the MoJET, the erosion is the more efficient at the early stage of the test since the gullies are relatively small at this time. To characterize the erosion "far from the critical shear stress", we thus choose to consider the erosion rate at the beginning of the test (or "initial erosion rate"). This erosion rate is simply the average one between 1 and 4 minutes. As remarked before, we do not consider the really first stage of erosion (i.e. the first minute) since it is certainly not 
representative of the erosion process. Figure 6(b) represents the initial erosion rate obtained from MoJET for the different textures.
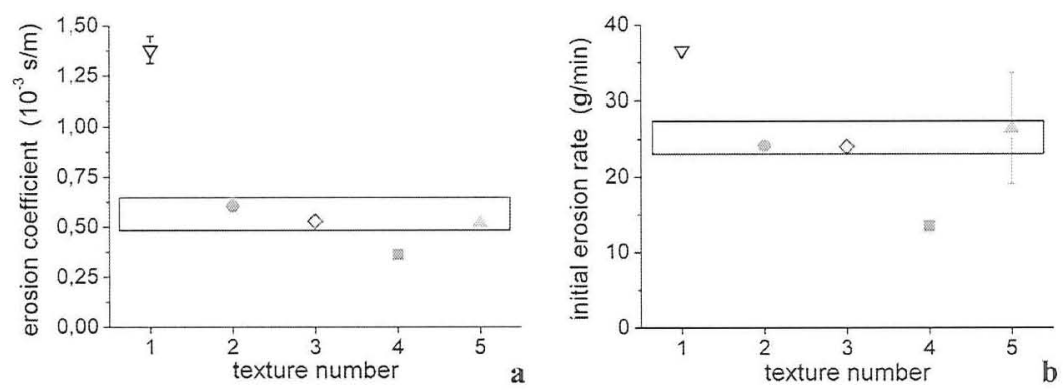

Figure 6. Tests comparison. (a) Erosion coefficient from HET. (b) Initial erosion rate from MoJET for the different textures.

Comparing figures 6(a) and 6(b), we find linkable results from the considered parameters issued from both tests. It could be expected that higher erosion coefficient from HET corresponds to higher initial erosion rate from MoJET. It is indeed what is observed. Texture 1 presents the highest erosion rate and the highest initial erosion rate where as texture 4 presents the lowest ones. The parameters from textures 2,3 and 5 are not distinct.

\section{Critical Shear Stress (HET) and Final Eroded Mass (MoJET)}

The second parameter characterizing HET is the critical shear stress $\tau_{c}$. It represents the shear stress that it is necessary to overcome in order to erode the soil. Figure 7(a) represents the critical shear stress obtained from HET for the different textures.

For the MoJET, the erosion efficiency decreases with time since the gullies that are full of water are deeper and the action of the water jets is thus less important. If the test lasts enough, one could expect that there is no more eroded mass (as the stress on the walls of the gullies is no more sufficient) and that the final cumulated eroded mass (at $12 \mathrm{~min}$ in the MoJET protocol) can so be linked to the critical shear stress. Figure 7(b) represents the final eroded mass (at $12 \mathrm{~min}$ ) obtained from MoJET for the different textures.

Comparing figures $7(\mathrm{a})$ and $7(\mathrm{~b})$, we find quite linkable results from the considered parameters issued from both tests. It could be expected that higher critical shear stress from HET corresponds to lower final eroded mass from MoJET. It is indeed what is observed for most of the textures. In particular, it should be noted that in contrary to the previous comparison (Fig. 6a-b), results for texture 1 aren't distinct from ones for textures 2 and 3 for both tests. This observation tends to prove that our differentiation of erosion coefficient and critical shear stress for HET on one side and initial erosion rate and final eroded mass for MoJET on the other has valid aspects. Results on texture 5 are more difficult to interpret and probably point out some of the limits to link the both tests. 

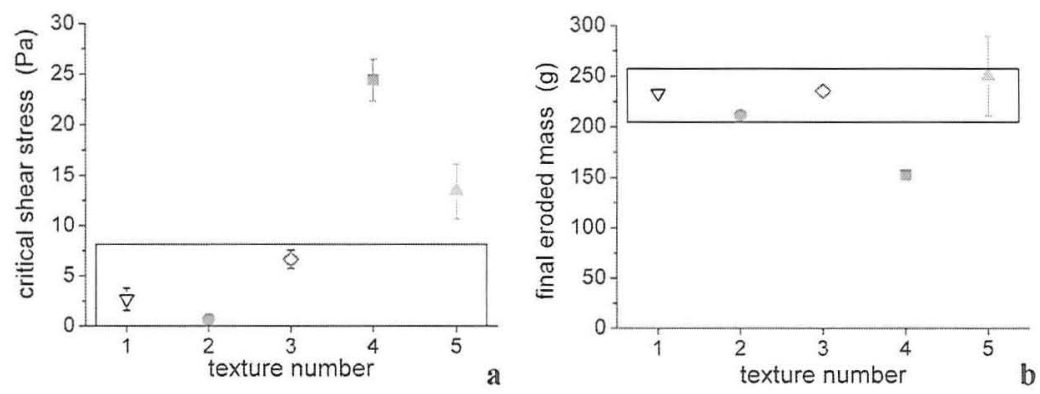

Figure 7. Tests comparison. (a) Critical shear stress from HET. (b) Final eroded mass from MoJET for the different textures.

\section{CONCLUSION AND PERSPECTIVES}

We present in this paper two methods to characterize erosion of soil: the Hole Erosion Test and the Mobile Jets Erosion Test, the latter allowing in situ test.

After using HET and MoJET on reference materials and reporting results, we sought to compare erosion characteristics issued from both test.

We thus qualitatively linked on one side the erosion coefficient obtained from HET and the initial erosion rate obtained from MoJET and on the other side the critical shear stress from HET and the final eroded mass from MoJET.

For a better comparison of the tests and understanding of the erosion process in the MoJET, a step forward would probably be to physically model the MoJET in order to obtain erosion parameters quantitatively comparable as the ones from HET. It would be of great interest since MoJET allows testing the soil in its real state and is most convenient and easy to use than HET.

\section{ACKNOWLEDGMENTS}

We thank Jean-Louis Tacita for valuable help with the test set-ups.

I. Haghighi benefits and T.L. Pham benefited from a student financial support delivered by the LCPC and the French public work ministry.

This work was partly financially supported by the French research program "ANR ERINOH".

\section{REFERENCES}

Arulanandan, K., Gillogley, E. and Tully, R. (1980). "Development of a quantitative method to predict critical shear stress and rate of erosion of natural undisturbed cohesive soils." Tech Rep. GL-80-5 , U.S. Army Engineers, Waterways Experiment station, Viksburg, MS EU.

ASTM (2005a). "Standard test method for identification and classification of dispersive clay soils by the pinhole test." Annual book of ASTM standards, Vol. 04.08, D4647-93(Reapp98). 
ASTM (2005b). "Standard test methods for laboratory compaction characteristics of soil using standard effort." Annual book of ASTM standards, Vol. 04.08, D698-00.

Bonelli, S., Brivois, O., Borghi, R. and Benahmed, N. (2006). "On modelling of piping erosion." Comptes Rendus de Mécanique, 334(8-9): 555-559.

Bendahmane, F., Marot, D. and Alexis, A. (2006). "Experimental parametric study of suffusion and backward erosion." Journal of Geotech. and Geoenv. Eng., 134(1): 57-67.

CFG (2004). "Recommandations pour l'utilisation des géosynthétiques dans la lutte contre l'érosion." www.cfg.asso.fr .

Guiton, M. (1998). "Ruissellement et risque majeur, Phénomènes, exemples et gestion spatiale des crues." Études et recherches des LPC, Série Environnement et Génie Urbain EG13.

Hanson, G.J. (1993). "Soil erodibility testing." US Patent $N^{\circ} 5,243,850$.

Hanson, G.J. (2004). "Apparatus, test procedures, and analytical methods to measure soil erodibility in situ." Applied Engineering in Agriculture, 20(4): 455-462.

Henensal, P. and Duchatel, F. (1990). "L'érodimètre à jets mobiles." Bulletin des Laboratoires des Ponts et Chaussées, 167, 47-53.

Henensal, P. (1993). "Lutte contre l'érosion avant, pendant et après les travaux: Les protections végétales et structurelles des surfaces et des pentes." Études et recherches des $L P C$, Série Géotechnique GT54.

LCPC and SETRA (1992). "Guide pour les Terrassements Routiers." Vol. 1 \& 2.

Perry, E. B. (1979). "Susceptibility of dispersive clay at Grenada dam, Mississippi, to piping and rainfall erosion." Tech Rep. GL-79-14, U.S. Army Engineers, Waterways Experiment station, Viksburg, MS EU.

Pham, T.L. (2008). "Erosion et dispersion des sols argileux par un fluide." PhD Thesis, Ecole Nationale des Ponts et Chaussées, Paris, France.

Pham, T.L., Chevalier, C., Reiffsteck, P.; Duc, M. and Guédon, S. (2010). "Improvement of hole erosion test and results on reference soils." in preparation.

Reiffsteck, P., Pham, T.L., Vargas, R. and Paihua, S. (2006). "Comparative study of superficial and internal erosion tests." 3rd International Conference on Scour and Erosion, Amsterdam.

Sanchez, R.L., Strutynsky, A.I. and Silver M.L. (1983). "Evaluation of the erosion potential of embankment core materials using the laboratory triaxial erosion test procedure." Tech Rep. GL-83-4, U.S. Army Engineers, Waterways Experiment station, Viksburg, MS EU.

Wan, C.F. and Fell, R. (2002). "Investigation of internal erosion and piping of soils in embankment dams by the slot erosion test and the hole erosion test." UNICIV Report, no. R-412.

Wan, C.F. and Fell, R. (2004). "Investigation of rate of erosion of soils in embankment dams." Journal of Geotech. and Geoenv. Eng., 30(4): 373-380. 